\title{
Contribution of respiratory tract infections to child deaths: a data linkage study
}

\author{
Pia Hardelid ${ }^{1 *}$, Nirupa Dattani ${ }^{1,2}$, Mario Cortina-Borja ${ }^{1}$ and Ruth Gilbert ${ }^{1}$
}

\begin{abstract}
Background: Respiratory tract infections (RTIs) are an important cause of death in children, and often contribute to the terminal decline in children with chronic conditions. RTIs are often underrecorded as the underlying cause of death; therefore the overall contribution of RTIs to child deaths and the potential preventability of RTI-related deaths have not been adequately quantified.

Methods: We analysed deaths in children resident in England who died of non-injury causes aged 28 days to 18 years between 2001 and 2010 using death certificates linked to a longitudinal hospital admission database. We defined deaths as RTI-related if RTIs or other respiratory conditions were recorded on death certificates or linked hospital records up to 30 days before death. We examined trends in mortality by age group, year and season (winter or summer) and determined the winter excess of RTI-related deaths using rate differencing techniques. We estimated the proportion of RTI-related deaths in children with chronic conditions.
\end{abstract}

Results: 22.4\% (5039/22509) of child deaths were RTI-related. RTI-related deaths declined by 2.3\% per year in infants aged 28 to 364 days between 2001 and 2010. No decline was observed for older children. On average there were 161 winter excess RTI-related deaths annually, accounting for 32\% of all RTI-related deaths. 89.0\% of children with RTI-related deaths had at least one chronic condition; neurological conditions were the most prevalent.

Conclusions: RTI-related deaths have not declined in the last decade except in infants. Targeted strategies to prevent the winter excess of RTIs and to treat RTIs in children, particularly children with chronic conditions, may reduce RTI-related deaths.

Keywords: Respiratory tract infection, Mortality, Children, Data linkage

\section{Background}

Respiratory tract infections (RTIs) are an important contributor to mortality in children worldwide [1-3]. Childhood mortality from respiratory conditions in England and Wales declined by $85 \%$ to $92 \%$ between the 1960s and the 1990s [4]. Yet, research into the mortality burden of specific pathogens have shown that influenza and respiratory syncytial virus (RSV) are estimated to cause up to 500 deaths in children in England and Wales every year [5,6]. This is despite national influenza and passive RSV vaccination programmes targeted at children deemed at high risk [7]. In 2009/10, three years after the introduction of seven-valent pneumococcal vaccine, 17 deaths per year were estimated to occur due to invasive

\footnotetext{
* Correspondence: p.hardelid@ucl.ac.uk

'Population, Policy and Practice Programme, UCL Institute of Child Health, 30 Guilford Street, London WC1N 1EH, UK

Full list of author information is available at the end of the article
}

pneumococcal disease in young children in England [8]. Few studies have examined the overall contribution of RTIs to childhood mortality, despite the importance to policy.

Quantifying the mortality burden of RTIs is not straightforward. Many previous studies rely on death certification data alone, however difficulties in accurately determining and recording causes of death are well described [9-11]. A further complication is that RTI-related deaths often occur in people with complex health problems, in whom RTIs contribute to the terminal decline [12]. It can therefore be difficult to determine whether the RTI was a cause or a consequence of the underlying health condition. This particularly becomes an issue when attempting to infer what proportion of RTI deaths are preventable through improvements in care or public health interventions such as vaccination. 
In this study we use coded clinical information from death certificates linked to electronic hospital admission records from all non-injury deaths in children to define deaths related to RTIs. Although the preventability of RTI-related deaths cannot be directly estimated using administrative data, we inferred preventability by looking at trends over time in RTI-related deaths, contrasting with trends in overall non-injury mortality, and estimating excess RTI-related deaths in winter. We also examine the proportion of RTI-related deaths that occur in children with chronic conditions.

\section{Methods}

\section{Data sources}

We analysed death certificates linked to a longitudinal hospital admission database for all resident children in England who died of non-injury related causes, based on their underlying cause of death, aged between 28 days and 18 completed years between January 2001 and December 2010. Linkage was carried out by the Trusted Data Linkage Service of the Health and Social Care Information Centre, using a deterministic algorithm based on NHS number, date of birth, sex and postcode. The linkage methods and accuracy are described in detail elsewhere [13]. Upon receipt of the data, we checked and cleaned them according to algorithms described previously [14]. The dataset included late-registered deaths until 7th $\mathrm{Au}$ gust 2012. Hospital admission records were obtained from the Hospital Episode Statistics (HES) database [15] and included any admissions to National Health Service (NHS) hospitals in England from April 1997. Death certificates and hospital records were coded using the International Classification of Diseases version 10 (ICD-10). Information on prescribing is not available in HES. Population denominators by age and year were obtained from the Office for National Statistics.

\section{Ethics}

All identifiers used for linkage were removed before data was sent to us. The data we used for the study were therefore anonymised, without personal identifiers. The data were collected as part of routine clinical practice or vital registration processes, not for research. Following guidance from the NHS Health Research Authority on using anonymised data collected as part of routine clinical practice for research purposes, [16] we did not seek ethical review of this study.

\section{Definition of RTI-related deaths and chronic conditions}

Since RTIs are likely to be variably coded in administrative health databases, we chose a broad definition of RTIrelated deaths to minimise undercounting. We identified RTI-related deaths using ICD-10 codes A37, J00-J22, which are specific for acute RTIs, based on codes listed anywhere on death certificates, or hospital discharge records where the date of the start of the hospital episode (an episode is a period of continuous care under one consultant [15]) was up to 30 days before death. We also conducted secondary analyses using a more sensitive cluster of codes indicating any respiratory condition, including RTIs (ICD-10 A37, J00-J99, R05, R06, E84, P75, Q30-Q34, Q790, G47.3, P22-P28), in children who died. The estimate of winter excess deaths related to any respiratory condition defined by the sensitive coding cluster could be interpreted as an upper bound on the number of excess RTI-related deaths.

Chronic conditions were defined as any condition that would require medical follow-up for one year or more, based on ICD-10 codes on death certificates or in hospital records up to one year before death [14]. Chronic conditions were grouped into eight categories for analyses: mental/behavioural, cancer/blood, chronic infection, respiratory, endocrine/metabolic/renal/digestive/genitourinary, musculoskeletal/skin, neurological/sensory and cardiac conditions.

\section{Statistical analyses}

All analyses were carried out according to age group at death (28 to 364 days, one to four years and five to 18 years). We calculated annual RTI-related mortality rates to examine trends over time. Poisson regression models were fitted with year as a linear term to determine whether any observed trends in annual mortality rates were statistically significant (defined as a likelihood ratio test $p<0.05)$ comparing an intercept only model and a model including year). If the trend was significant, possible change points were examined using piecewise generalised linear models to determine the change point location [17]. Since these models were not nested, we used the Akaike Information Criterion (AIC) to determine whether a model including a change point improved the overall fit. We compared trends in RTI-related mortality rates to those for all non-injury causes.

We assumed that some of the winter excess of RTIrelated deaths could potentially be prevented through prompt identification and treatment (including with antibiotics), effective management of chronic conditions (such as enhanced care for children with breathing support), universal vaccination strategies with effective vaccines, or improved hygiene measures such as hand washing. To examine seasonality we plotted weekly and monthly mortality rates per 100,000 population. Monthly rates were plotted using circular plots, using the season library in R [18]. RTI mortality rates in winter (defined as week 40 to week 20 the following year) and summer (week 21 to week 39) were calculated for the whole study period, adjusting the population denominator to account for the differing person-time at risk. This definition of a winter period was chosen since it covers the weeks during which 
respiratory infection surveillance programmes are active in England [19]. We estimated the number of excess RTIrelated deaths in winter periods compared with summer periods using rate differencing techniques $[6,20]$. Further details can be found in the Additional file 1. We calculated the number of excess RTI-related deaths in winter as a percentage of all RTI-related deaths, and as a percentage of all non-injury deaths occurring in winter.

We calculated the proportion of RTI-related deaths that occurred in children with chronic conditions, according to type of chronic condition and age group. Denominators for children with and without chronic conditions were not available. Therefore we could not use rate differencing techniques to estimate the number of excess RTI-related deaths according to chronic condition type. Instead, we compared the proportion of all RTI-related deaths which occurred in winter in children with and without chronic conditions respectively. We used $\chi^{2}$ tests to test for differences in the proportions of RTI-related deaths occurring in children with chronic conditions. These analyses were carried out using the RTI-specific code lists to define RTIrelated deaths.

Methods and results of sensitivity analyses are given in the Additional file 1. All statistical analyses were carried out in $\mathrm{R}$ version 3.0.1 [21].

\section{Results}

The study population comprised 22509 children who died of non-injury causes between 2001 and 2010, of whom 9208 were aged between 28 and 364 days (40.9\%), 4310 one to four years (19.1\%) and 8991 five to 18 years (39.9\%). 14180 children (63.0\%) were linked to at least one hospital record within the last thirty days before death.

Overall, 3339 children who died of non-injury causes had an RTI listed on their death certificate (14.8\%), and 5039 children (22.4\%) had an RTI listed on death certificates or on hospital records up to 30 days before death. 10169 children (45.2\%) had at least one respiratory condition (including RTIs and other respiratory conditions) listed on their death certificates or on hospital records up to 30 days before death. This was equivalent to 504 RTI-related deaths and 1017 any respiratory conditionrelated deaths per year respectively. 18443 children had at least one chronic condition (81.9\%).

Recording of RTIs and respiratory conditions on death certificates and hospital records was generally non-specific (Additional file 1: Table S1), that is, not mentioning specific pathogens. There was weak agreement between hospital records and death certificates in recording of any respiratory condition (Additional file 1: Table S2); with only $66.1 \%$ agreement for children who died in hospital. Mortality rates for RTIs and other respiratory conditions were between two and eight times higher when including all causes listed on death certificates and linked hospital records up to one month before death compared to using the underlying cause only (Additional file 1: Table S3).

\section{Annual trends in mortality rates from RTIs}

Results from the Poisson regression models showed that RTI-related deaths declined significantly between 2001 and 2010 by an average of $2.3 \%$ per year (95\% CI $0.6 \%$, $4.0 \%$ ) in children aged between 28 and 364 days, as shown in Figure 1 (LR test $p=0.01$ for year as a linear trend compared to intercept only model). This amounted to a total decline of $28.9 \%$ between 2001 (a mortality rate of $30.1 / 100,000$ population) and 2010 (when the mortality rate had declined to 21.4/100,000 population). We detected a change point in the series in 2003, prior to which the decline was more pronounced. No significant declines were observed for RTI-related deaths in older children. No trends were observed for deaths mentioning any respiratory condition in any age group. In contrast, non-injury all-cause mortality rates showed significant annual declines of $2.2 \%$ in children aged 28 to 364 days, $2.4 \%$ in one to four year olds and $2.6 \%$ in five to 18 year olds during the same period (Figure 1).

\section{Estimation of excess winter RTI deaths}

A seasonal pattern was observed for mortality involving respiratory conditions, particularly for RTI-related deaths (Figure 2 and Table 1). Mortality rates peaked in December for both specific RTI-related mortality and for deaths involving any respiratory condition, but seasonal variation in respiratory mortality was particularly evident in one to four year old children (Figures 3 and 4).

There were 161 excess winter RTI-related deaths in children aged between 28 days and 18 years each year (Table 1), accounting for $32 \%$ of all RTI-related deaths. If the more sensitive indicator, excess deaths with any respiratory condition mentioned, was used, up to 194 excess winter RTI-related deaths occurred annually. Although the highest RTI-related mortality rates were observed in children aged less than one year, excess winter RTI-related deaths accounted for up to $41 \%$ of the total number of RTI-related deaths and up to $22 \%$ of all winter deaths in one to four year olds (Table 1).

\section{RTI-related deaths in children with chronic conditions}

Among children whose deaths were RTI-related, 89.0\% of 5039 children had one or more chronic conditions, compared to $79.9 \%$ of 17470 children who did not die with an RTI ( $\chi^{2}$ test $\left.p<0.001\right)$. The proportion of children whose deaths were RTI-related who also had a chronic condition increased with age. $79.3 \%$ of children aged between 28 and 364 days (of a total of 1512 children), $89.9 \%$ of children aged one to four years (1411 children) and $95.3 \%$ of five to 18 year old children (2116 children) who died with RTIs had a chronic condition $\left(\chi^{2}\right.$ test for 


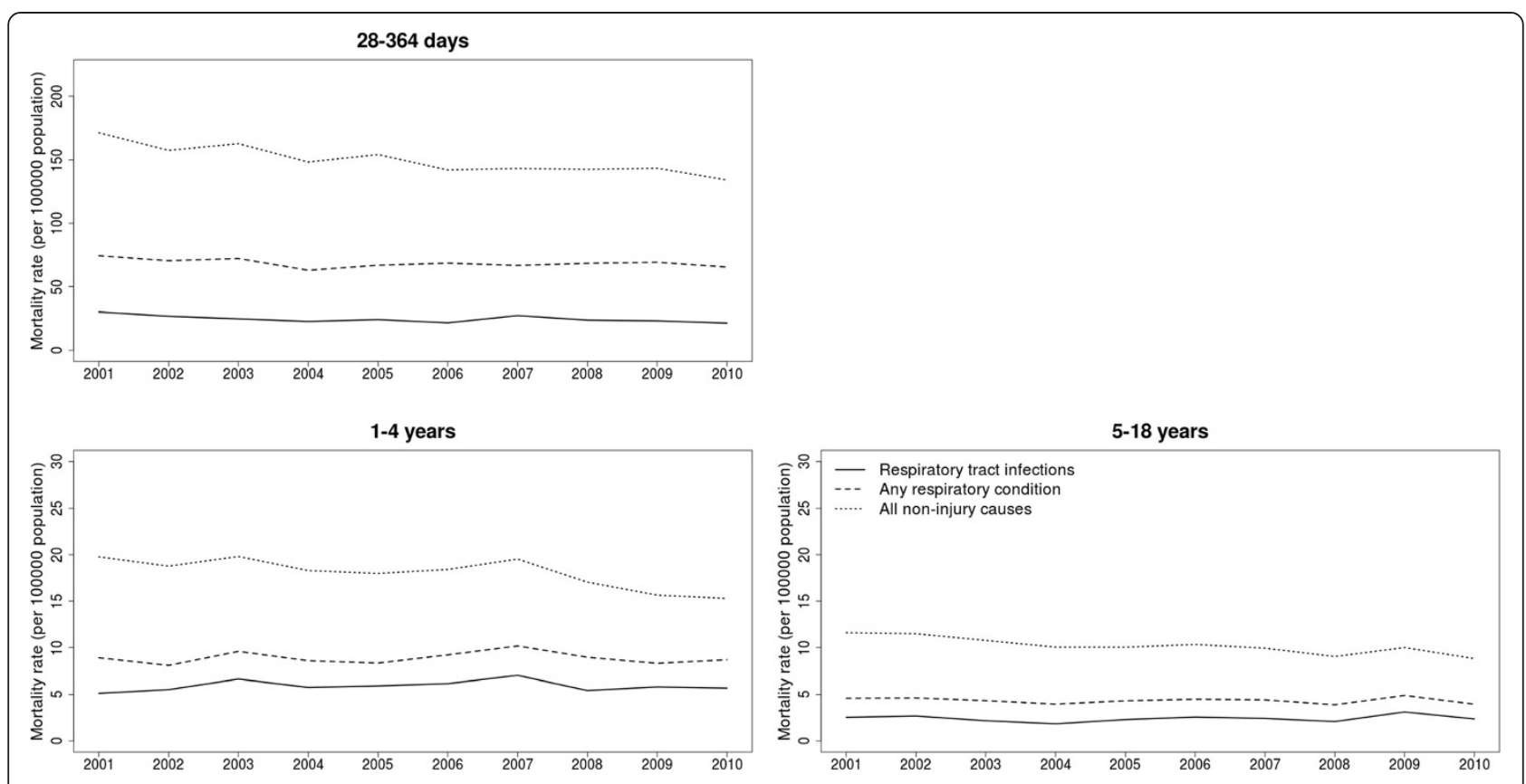

Figure 1 Mortality rates (per 100,000 population) for RTIs, any respiratory condition and all non-injury causes by age group, $2001-2010$. Note different $y$-axis scales for children aged less than one year.

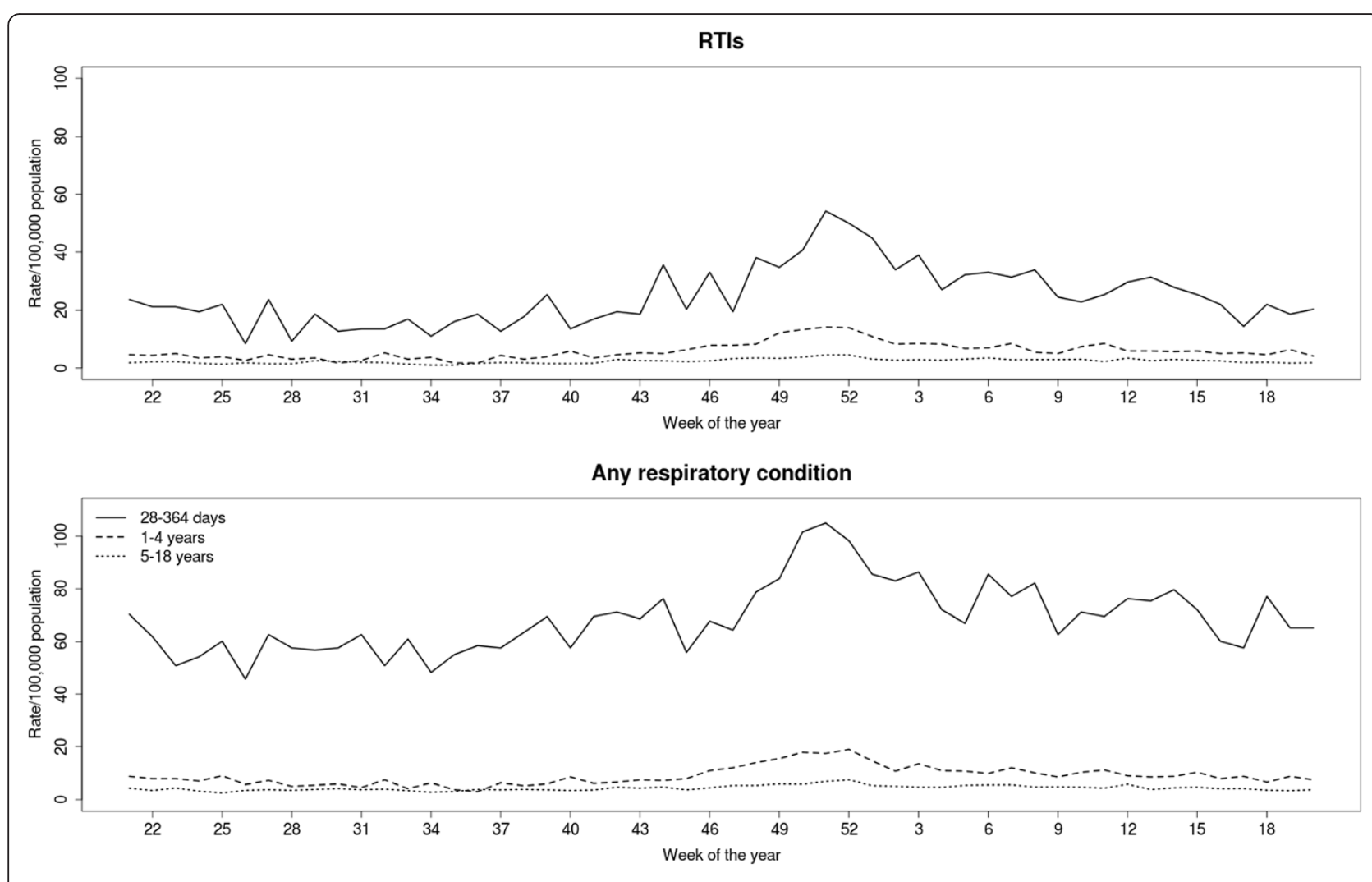

Figure 2 Mortality rates (per 100,000 population) by week of the year, age group for deaths involving RTIs and any respiratory condition. 
Table 1 Mortality rates by season, rate differences (both per 100,000 population), and rate ratios comparing winter and summer, for children with RTls only and any respiratory condition, with winter excess deaths shown as estimated number and percentage of all non-injury winter deaths and all RTI-related deaths, by age group and indicator used, England, 2001-2010

\begin{tabular}{|c|c|c|c|c|c|c|c|c|}
\hline $\begin{array}{l}\text { Indicator } \\
\text { used }\end{array}$ & $\begin{array}{l}\text { Rate }_{\text {winter }} \\
(95 \% \mathrm{Cl})\end{array}$ & $\begin{array}{l}\text { Rate }_{\text {summer }} \\
(95 \% \text { Cl) }\end{array}$ & $\begin{array}{l}\text { Rate } \\
\text { ratio } \\
(95 \% \mathrm{Cl})\end{array}$ & $\begin{array}{l}\text { Rate } \\
\text { difference }{ }_{\text {winter-summer }} \\
(95 \% \mathrm{Cl})^{+}\end{array}$ & $\begin{array}{l}\text { Total number of excess } \\
\text { RTI-related deaths in } \\
\text { winter (range)* }\end{array}$ & $\begin{array}{l}\text { Average number of excess } \\
\text { RTI-related deaths each } \\
\text { winter (range)* }\end{array}$ & $\begin{array}{l}\text { Winter excess as } \% \\
\text { of total non-injury } \\
\text { deaths in winter** }\end{array}$ & $\begin{array}{l}\text { Winter excess as } \% \\
\text { of total RTI-related } \\
\text { deaths*** }\end{array}$ \\
\hline
\end{tabular}

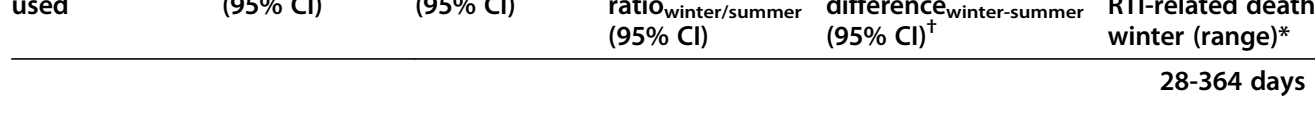

$\begin{array}{llllr}\text { RTIs only } & 28.7(27.1,30.5) & 17.2(15.5,19.0) & 1.68(1.49,1.88) & 11.59(9.19,13.98) \\ \text { Any respiratory } & 74.4(71.7,77.1) & 58.1(54.9,61.3) & 1.28(1.20,1.37) & 16.23(12.08,20.38)\end{array}$

$$
\begin{aligned}
& 454(360,548) \\
& 636(474,799)
\end{aligned}
$$

$$
\begin{aligned}
& 45(36,55) \\
& 64(47,80)
\end{aligned}
$$

\section{1-4 years}

$\begin{array}{llll}576(487,664) & 58(49,66) & 18.8 \% & 40.8 \% \\ 665(553,776) & 66(55,78) & 21.8 \% & 31.2 \%\end{array}$

RTIs only

$$
7.3(6.8,7.7)
$$

$3.5(3.1,3.9) \quad 2.08(1.84,2.37)$

$3.78(3.20,4.36)$

Any respiratory $10.5(10.0,11.0)$

$$
6.1(5.6,6.7) \quad 1.71(1.55,1.89)
$$

$4.37(3.63,5.10)$

condition

\section{5-18 years}

$\begin{array}{lrrr}583(471,695) & 58(47,69) & 9.6 \% & 27.6 \% \\ 640(485,794) & 64(49,79) & 10.6 \% & 16.7 \%\end{array}$

\section{All ages}

\begin{tabular}{llllllll} 
RTIs only & $5.0(4.9,5.2)$ & $2.9(2.7,3.1)$ & $1.74(1.63,1.86)$ & $2.1(1.9,2.4)$ & $1613(1442,1784)$ & $161(144,178)$ & $10.5 \%$ \\
$\begin{array}{l}\text { Any respiratory } \\
\text { condition }\end{array}$ & $9.6(9.3,9.8)$ & $7.0(6.7,7.2)$ & $1.37(1.31,1.43)$ & $2.6(2.3,2.9)$ & $1941(1691,2191)$ & $194(169,219)$ \\
\hline
\end{tabular}

${ }^{\dagger}$ All differences in RTI-related mortality rates between winter and summer are statistically significant, Likelihood ratio test $p<0.001$ for all ages.

*Range is estimated using the lower and upper end of the $95 \%$ confidence interval for the rate difference.

**Using point estimate for excess RTI-related deaths. Total non-injury deaths in winter by age group: $28-264$ days $=6244,1-4$ years $=3056,5-18$ years $=6046$.

***Using point estimate for excess RTI-related or any respiratory condition related deaths.

Total deaths by age group for RTIs only: $28-264$ days $=1512,1-4$ years $=1411,5-18$ years $=2116$.

Total deaths by age group for any respiratory condition: $28-264$ days $=4219,1-4$ years $=2129,5-18$ years $=3821$. 


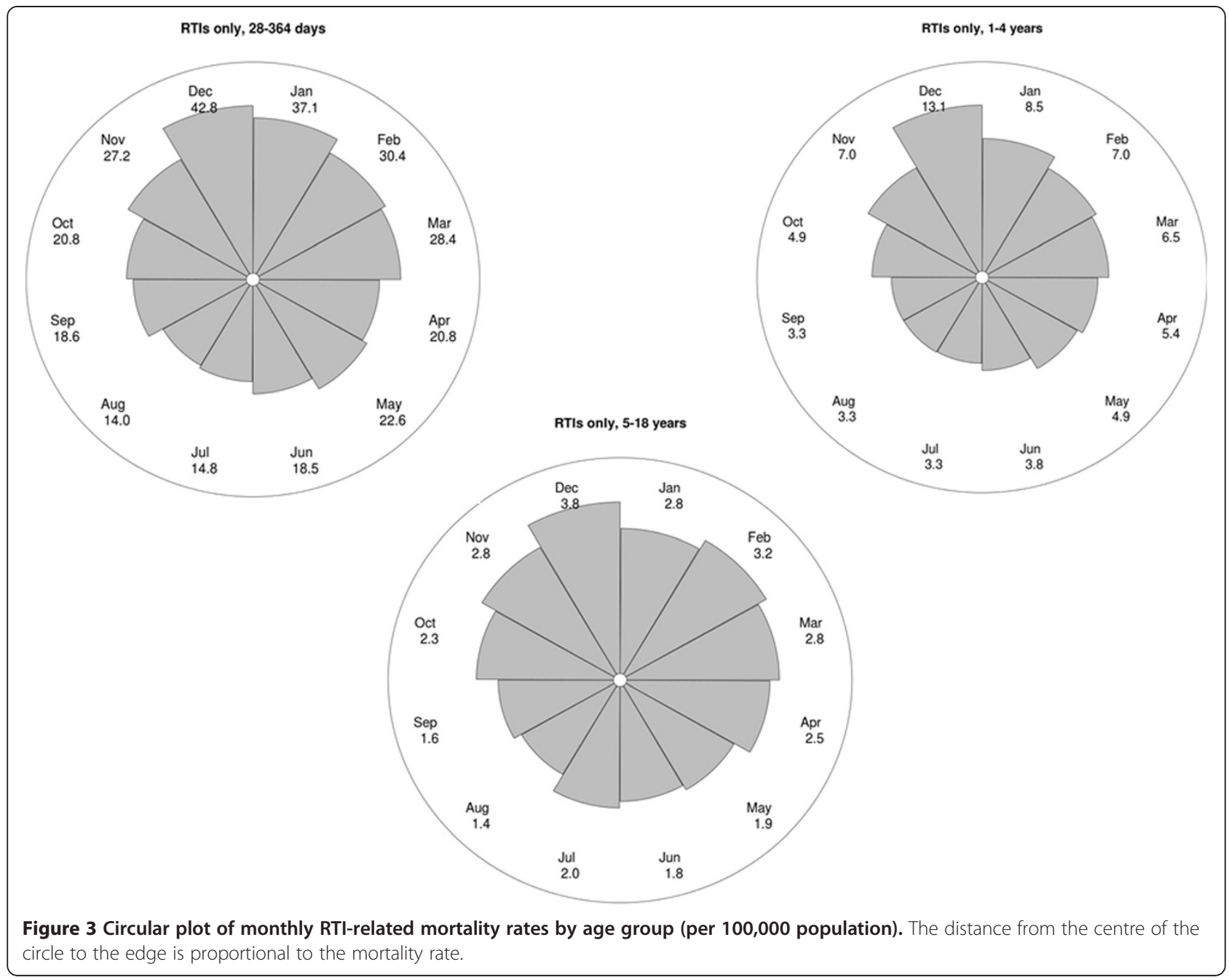

trend $p<0.001)$. Neurological/sensory conditions were the most common chronic conditions among children who died with RTIs; $64.6 \%$ of children whose deaths were RTIrelated had a neurological sensory condition (Table 2). Of the 4483 children with one or more chronic conditions whose death was RTI-related, $75.2 \%$ had chronic conditions from two or more of the eight chronic condition groups.

Of the 4483 children who died with RTIs and chronic conditions, $74.7 \%$ (3349 children) died in winter. This was significantly lower than among children who died with RTIs but without chronic conditions, among whom $79.7 \%$ (443 of 556 children) died in winter $\left(\chi^{2}\right.$ test $p=0.01$ ), although the absolute difference in proportions was small.

\section{Discussion}

There has been no decline in RTI-related mortality in children aged one year and above since 2001, despite significant declines in all-cause non-injury deaths. We estimated that an average of 161 excess RTI-related deaths occurred each winter in children aged 28 days to 18 years in England. This excess accounts for $32 \%$ of all RTI-related deaths.
Although the highest mortality rates from RTIs in winter were found in children aged between one and 11 months, children aged between one and four years experienced the highest number of excess winter RTI-related deaths as a proportion of all RTI-related deaths. $89 \%$ of children who died from RTIs had a chronic condition; $65 \%$ had a neurological/sensory condition.

This was a large study of all deaths in children aged 28 days to 18 years in England during a ten year period. Since deaths from RTIs are relatively rare in children compared to the elderly, the population wide coverage of the study was necessary to ensure sufficient cases to estimate the number of RTI-related deaths with reasonable precision.

We used linked data involving death certificates and hospital admissions which allowed identification of deaths where an RTI was severe enough to warrant recording on a hospital database shortly preceding death, even if this was not recorded on death certificates. Use of linked hospital admission data increased the sensitivity of our analyses for detecting RTI-related deaths and the presence of chronic 


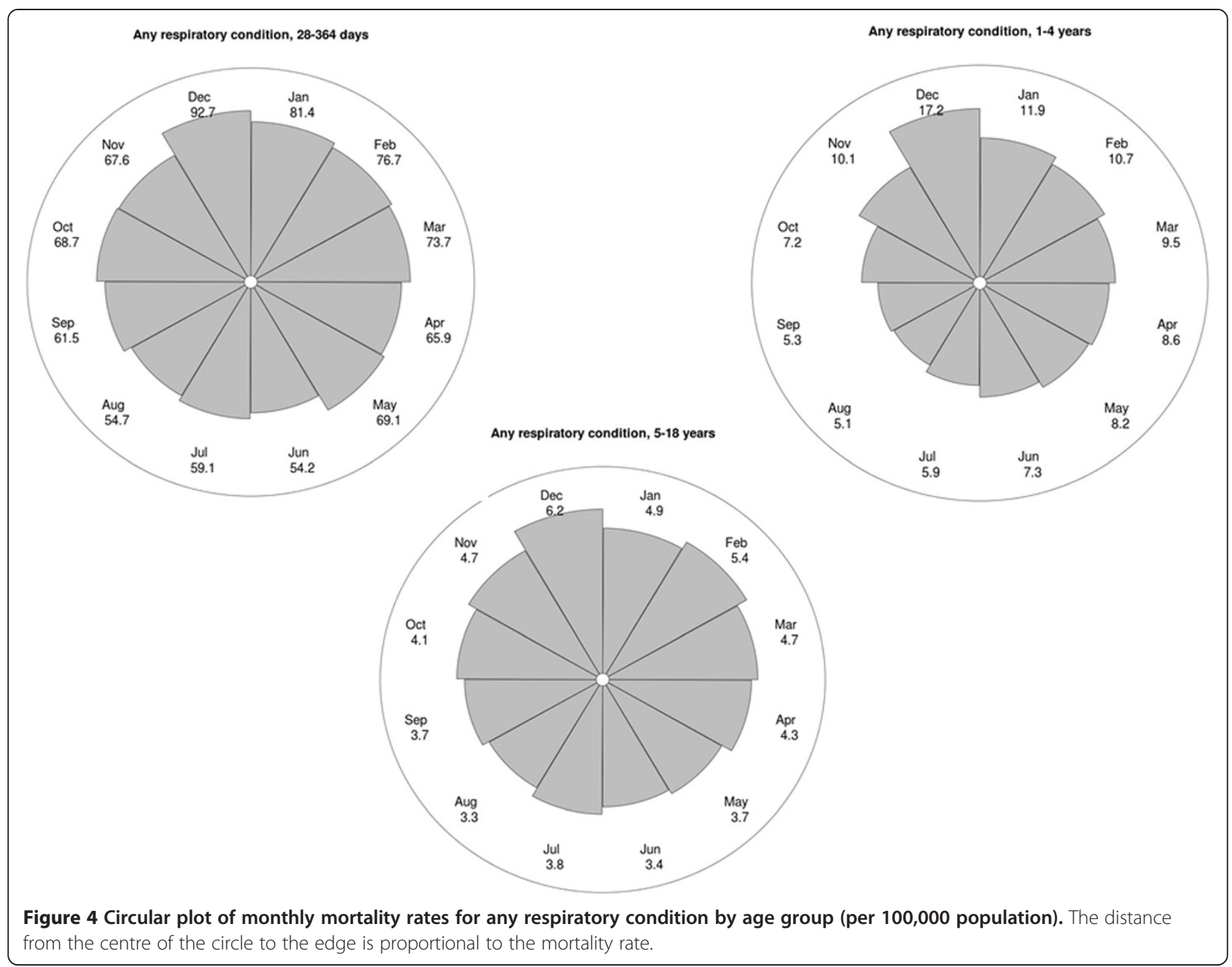

Table 2 Number and percentage (in brackets) of children who died with RTIs*, by type of chronic condition and age group

\begin{tabular}{|c|c|c|c|c|c|c|c|c|}
\hline & $\begin{array}{c}\text { Mental/ } \\
\text { behavioural }\end{array}$ & $\begin{array}{l}\text { Cancer/ } \\
\text { blood }\end{array}$ & $\begin{array}{c}\text { Chronic } \\
\text { infections }\end{array}$ & Respiratory & $\begin{array}{c}\text { Endocrine/metabolic/renal/ } \\
\text { digestive/genitourinary }\end{array}$ & $\begin{array}{l}\text { Musculoskeletal/ } \\
\text { skin }\end{array}$ & $\begin{array}{c}\text { Neurological/ } \\
\text { Sensory }\end{array}$ & Cardiac \\
\hline 28-364 days & $33(2.2)$ & $161(10.6)$ & $36(2.4)$ & $554(36.6)$ & $487(32.2)$ & $208(13.8)$ & 799 (52.8) & $544(36.0)$ \\
\hline \multicolumn{9}{|l|}{$n=1512$} \\
\hline $1-4$ years & $229(16.2)$ & $257(18.2)$ & $38(2.7)$ & $623(44.2)$ & $642(45.5)$ & $227(16.1)$ & $952(67.5)$ & $339(24.0)$ \\
\hline \multicolumn{9}{|l|}{$n=1411$} \\
\hline $5-18$ years & $530(25.0)$ & $496(23.4)$ & $68(3.2)$ & $889(42.0)$ & $870(41.1)$ & 575 (27.2) & 1505 (71.1) & 315 (14.9) \\
\hline \multicolumn{9}{|l|}{$n=2116$} \\
\hline All ages & 792 (15.7\%) & 914 (18.1) & $142(2.8)$ & 2066 (41.0) & 1999 (39.7) & $1010(20.0)$ & $3256(64.6)$ & 1198 (23.8) \\
\hline$n=5039$ & & & & & & & & \\
\hline
\end{tabular}

*RTI-related deaths are defined using the following ICD-10 codes: A37, J00-J22.

Note that percentages will add up to more than $100 \%$ since chronic condition groups are not mutually exclusive and children can have conditions from more than one group. 
conditions, compared to using death certificates alone. Through linkage, we were able to identify a further 1700 children (amounting to 34\% of the total number of cases) who had an RTI on their hospital record, but this was not mentioned on the death certificate.

We identified relatively poor agreement between hospital records and death certificates in recording of any respiratory condition $(66.1 \%$ agreement for deaths in hospital and $73.2 \%$ agreement for deaths outside hospital). Poor agreement between hospital records and death certificates has been reported previously [22-24]. Data linkage provides a method of validating the diagnostic information recorded in these datasets, as well as a strategy to overcome some of the under-recording of diagnoses on death certificates.

The estimate of the proportion of children who had an RTI in the month before death is likely to be an underestimate, as linkage was limited to hospital records. Further linkage to primary care databases and to data on diagnoses and treatment provided in hospices would allow an examination of the role of RTIs in children who died but who had not had a hospital admission in the month before death. However, there are currently no national-level primary care or hospice datasets available in England.

We could not compare differential risks of RTI-related mortality according to type of chronic condition since we did not have information on all children (alive and dead) who were affected according to type of chronic condition. Future studies using longitudinal hospital data from birth in children are required. These can be used to estimate RTI-related death rates according to type of chronic condition and other determinants such as deprivation level, birth weight and gestational age.

Although our method allowed us to estimate the number of children whose deaths were RTI-related, it was not possible to determine whether a child died of an RTI. The exact chronology of events is difficult to infer from hospital databases, since dates of infection onset or diagnoses were not available. Further linkage to laboratory datasets would allow the quantification of deaths from specific pathogens and more detailed validation of diagnostic coding. This would also allow characterisation and subanalyses of community and hospital acquired infections.

We inferred preventability using trends over time and differences between winter and summer in RTI-related mortality rates. The rate differencing technique used to estimate excess winter RTI-related deaths was a crude attempt to estimate the number of deaths that may be preventable. However, the vast majority of children whose deaths were RTI-related had a chronic condition, and of them, $75 \%$ had conditions affecting more than one body system, indicating complex health problems. It is therefore unlikely that all of these deaths could be prevented, even through the use of interventions that may be highly effective in healthy children. In children with very complex health problems, it is possible that antibiotic treatment or influenza or pneumococcal vaccination may only delay death, not prevent the death completely. Such a 'harvesting' effect has been described in relation to the effect of extreme weather on respiratory mortality in adults, [25] but there is little evidence regarding such effects in children, most likely due to mortality being relatively rare at younger ages. In addition, it is likely that the number of excess winter deaths represents only a small proportion of all preventable RTI deaths throughout the year. Case note reviews of a subset of these deaths could help to determine whether an RTI was likely to be the cause of the death and whether an RTI-related death could have been delayed or prevented.

Previous studies have focused on estimating the mortality burden of particular pathogens, including influenza and RSV, using statistical models. Assuming the majority of RTI-related deaths in children are due to those two viruses, our results are broadly compatible with estimates of influenza and RSV related deaths in England [6], although our study included a later time period. The studies by Pitman et al. [26] and Hardelid et al. [5] are not directly comparable to ours as they also include neonates.

Chronic conditions have previously been recognised as risk factors for severe outcomes of RTIs in children, [27-30] but there is a lack of evidence regarding which interventions are effective for these children [27-30]. For example, Osterholm et al. [31] estimated that live attenuated influenza vaccine (now recommended for children aged two to four years in the UK) is $83 \%$ effective at preventing confirmed influenza infection in healthy children. However, there is scant evidence for vaccine effectiveness in children with chronic conditions, particularly for preventing deaths. Likewise, industry-funded trials have shown that palivizumab reduces hospital admissions for RSV in high risk children by $50 \%$, but with no evidence of significant reductions in mortality [32]. Pneumococcal vaccine effectiveness has been estimated at 75\%, [33] however since the case fatality rate for invasive pneumococcal disease is around $4 \%$ in children, [34] the effect on mortality is likely to be small.

\section{Conclusions}

Over 500 RTI-related deaths occur in children in England each year. Up to one third of these are related to seasonal variation, and a subset may be preventable. Nearly $90 \%$ of RTI-related deaths occur in children with chronic conditions, and the highest incidence is in children aged less than one year. Effective implementation of prevention and treatment of RTIs is likely to lower the mortality burden in children, particularly in younger children aged less than five years. The use of routinely collected data offer the possibility of regular assessment of mortality rates to 
determine the mortality impact of RTIs and the effect of public health and treatment interventions.

\section{Availability of supporting data}

Sharing of the raw data used for this study is not allowed under agreements with the data providers, due to the possibility of individual disclosure.

\section{Additional file}

\section{Additional file 1: Supplementary text and tables.}

\section{Abbreviations}

HES: Hospital episode statistics; ICD-10: International Classification of Diseases version 10; NHS: National Health Service; RSV: Respiratory syncytial virus; RTI: Respiratory tract infection.

\section{Competing interests}

The authors declare that they have no competing interests.

\section{Authors' contributions}

RG and PH conceptualised the study. RG oversaw data analyses and contributed to drafting the final manuscript. PH carried out the data cleaning and analyses and drafted the final manuscript. MCB contributed to data analyses and contributed to drafting the final manuscript. ND negotiated access to data sources, contributed to data cleaning and analysis and contributed to drafting the manuscript. All authors approved the final manuscript as submitted.

\section{Acknowledgements}

We gratefully acknowledge the Health and Social Care Information Centre and the Office for National Statistics for providing the linked data for this study. PH and RG are members of the London Farr Institute for Health Informatics.

This study was part of the Child Health Reviews UK programme, which was commissioned by the Healthcare Quality Improvement Partnership (HQIP) on behalf of NHS England, NHS Wales, the Health and Social care division of the Scottish government, The Northern Ireland Department of Health, Social Services and Public Safety (DHSSPS) the States of Jersey, Guernsey, and the Isle of Man. PH is funded by a National Institute for Health Research postdoctoral fellowship. This article represents independent research funded by the National Institute for Health Research (NIHR). The views expressed are those of the authors and not those of the NHS, the NIHR or the Department of Health. The study benefitted from infrastructure and academic support at the Farr Institute of Health Informatics Research London.

\section{Author details}

${ }^{1}$ Population, Policy and Practice Programme, UCL Institute of Child Health, 30 Guilford Street, London WC1N 1EH, UK. ${ }^{2}$ Centre for Maternal and Child Health Research, City University, London, UK.

Received: 31 July 2014 Accepted: 7 November 2014

Published: 20 November 2014

\section{References}

1. Williams BG, Gouws E, Boschi-Pinto C, Bryce J, Dye C: Estimates of worldwide distribution of child deaths from acute respiratory infections. Lancet Infect Dis 2002, 2(1):25-32.

2. Mulholland K: Global burden of acute respiratory infections in children: implications for interventions. Pediatr Pulmonol 2003, 36(6):469-474.

3. Rudan I, O'Brien KL, Nair H, Liu L, Theodoratou E, Qazi S, Luksic I, Fischer Walker $\mathrm{CL}$, Black RE, Campbell H: Epidemiology and etiology of childhood pneumonia in 2010: estimates of incidence, severe morbidity, mortality, underlying risk factors and causative pathogens for 192 countries. J Glob Health 2013, 3(1):010401.
4. Panickar JR, Dodd SR, Smyth RL, Couriel JM: Trends in deaths from respiratory illness in children in England and Wales from 1968 to 2000. Thorax 2005, 60(12):1035-1038.

5. Hardelid P, Pebody RG, Andrews N: Mortality caused by influenza and respiratory syncytial virus by age group in England and Wales 1999-2010. Influenza Other Respi Viruses 2012, 7(1):35-45.

6. Fleming DM, Pannell RS, Cross KW: Mortality in children from influenza and respiratory syncytial virus. J Epidemiol Community Health 2005, 59(7):586-590.

7. Salisbury D, Ramsay M, Noakes K: Immunisation Against Infectious Disease: The Green Book. London: The Stationery Office; 2006.

8. van Hoek AJ, Andrews N, Waight PA, George R, Miller E: Effect of serotype on focus and mortality of invasive pneumococcal disease: coverage of different vaccines and insight into non-vaccine serotypes. PLoS One 2012, 7(7):e39150.

9. O'Malley KJ, Cook KF, Price MD, Wildes KR, Hurdle JF, Ashton CM: Measuring diagnoses: ICD code accuracy. Health Serv Res 2005, 40(5 Pt 2):1620-1639.

10. Guite HF, Burney PG: Accuracy of recording of deaths from asthma in the UK: the false negative rate. Thorax 1996, 51(9):924-928.

11. Maudsley G, Williams EM: Inaccuracy in death certification-where are we now? J Public Health Med 1996, 18(1):59-66.

12. Sachedina N, Donaldson LJ: Paediatric mortality related to pandemic influenza A H1N1 infection in England: an observational populationbased study. Lancet 2010, 376(9755):1846-1852.

13. Health and Social Care Information Centre: A guide to linked mortality data from hospital episode statistics and the office for national statistics. [http://www.hscic.gov.uk/media/11668/HES-ONS-Mortality-Data-Guide/pdf/ hes_ons_\%20mortality_data_guide.pdf]

14. Hardelid P, Dattani N, Davey J, Pribramska I, Gilbert R: Overview of child deaths in the four UK countries. [http://www.rcpch.ac.uk/system/files/protected/page/ CHR-UK\%20MODULE\%20B\%20REVISED\%20v2\%2015112013.pdf]

15. Health and Social Care Information Centre: HES user guide. [http://www. hscic.gov.uk/hes]

16. NHS Health Research Authority: Does my project require review by a research ethics committee? [http://www.hra.nhs.uk/documents/2013/09/ does-my-project-require-rec-review.pdf]

17. Sonderegger D: SiZeR: significant zero corssings. [http://cran.r-project.org/ web/packages/SiZer/SiZer.pdf]

18. Barnett AG, Dobson AJ: Analysing Seasonal Health Data. Berlin: Springer; 2010.

19. Public Health England: Surveillance of influenza and other respiratory viruses, including novel respiratory viruses, in the United Kingdom: winter 2012/2013. [https:/www.gov.uk/government/uploads/system/uploads/attachment_data/file/ 325217/Annual_flu_report_winter_2012_to_2013.pdf]

20. Jansen AGSC, Sanders EAM, Wallinga J, Groen EJ, van Loon AM, Hoes AW, Hak E: Rate-difference method proved satisfactory in estimating the influenza burden in primary care visits. J Clin Epidemiol 2008, 61(8):803-812.

21. R Core Team: R: a language and environment for statistical computing. [http://www.R-project.org/]

22. Johansson LA, Westerling R: Comparing Swedish hospital discharge records with death certificates: implications for mortality statistics. Int J Epidemiol 2000, 29(3):495-502.

23. Johansson LA, Westerling R: Comparing hospital discharge records with death certificates: can the differences be explained? J Epidemiol Community Health 2002, 56(4):301-308.

24. Gittelsohn A, Senning J: Studies on the reliability of vital and health records: I. Comparison of cause of death and hospital record diagnoses. Am J Public Health 1979, 69(7):680-689.

25. Braga AL, Zanobetti A, Schwartz J: The effect of weather on respiratory and cardiovascular deaths in 12 U.S. cities. Environ Health Perspect 2002, 110(9):859-863.

26. Pitman RJ, Melegaro A, Gelb D, Siddiqui MR, Gay NJ, Edmunds WJ: Assessing the burden of influenza and other respiratory infections in England and Wales. J Infect 2007, 54(6):530-538.

27. Neuzil KM, Wright PF, Mitchel EF, Griffin MR: The burden of influenza illness in children with asthma and other chronic medical conditions. J Pediatr 2000, 137(6):856-864.

28. Pebody RG, McLean E, Zhao H, Cleary P, Bracebridge S, Foster K, Charlett A, Hardelid P, Waight P, Ellis J, Bermingham A, Zambon M, Evans B, Salmon R, McMenamin J, Smyth B, Catchpole M, Watson J: Pandemic Influenza A (H1N1) 2009 and mortality in the United Kingdom: risk factors for death, April 2009 to March 2010. Euro Surveill 2010, 15(20). 
29. Kristensen K, Hjuler T, Ravn H, Simoes EA, Stensballe LG: Chronic diseases, chromosomal abnormalities, and congenital malformations as risk factors for respiratory syncytial virus hospitalization: a population-based cohort study. Clin Infect Dis 2012, 54(6):810-817.

30. Eriksson M, Bennet R, Rotzen-Ostlund M, von Sydow M, Wirgart BZ: Population-based rates of severe respiratory syncytial virus infection in children with and without risk factors, and outcome in a tertiary care setting. Acta Paediatr 2002, 91(5):593-598.

31. Osterholm MT, Kelley NS, Sommer A, Belongia EA: Efficacy and effectiveness of influenza vaccines: a systematic review and meta-analysis. Lancet Infect Dis 2012, 12(1):36-44.

32. Andabaka T, Nickerson JW, Rojas-Reyes MX, Rueda JD, Bacic Vrca V, Barsic B: Monoclonal antibody for reducing the risk of respiratory syncytial virus infection in children. Cochrane Database Syst Rev 2013, 4:CD006602.

33. Andrews NJ, Waight PA, Burbidge P, Pearce E, Roalfe L, Zancolli M, Slack M, Ladhani SN, Miller E, Goldblatt D: Serotype-specific effectiveness and correlates of protection for the 13-valent pneumococcal conjugate vaccine: a postlicensure indirect cohort study. Lancet Infect Dis 2014, 14(9):839-846.

34. Ladhani SN, Slack MP, Andrews NJ, Waight PA, Borrow R, Miller E: Invasive pneumococcal disease after routine pneumococcal conjugate vaccination in children, England and Wales. Emerg Infect Dis 2013, 19(1):61-68.

doi:10.1186/1471-2458-14-1191

Cite this article as: Hardelid et al: Contribution of respiratory tract infections to child deaths: a data linkage study. BMC Public Health 2014 14:1191.

\section{Submit your next manuscript to BioMed Central and take full advantage of:}

- Convenient online submission

- Thorough peer review

- No space constraints or color figure charges

- Immediate publication on acceptance

- Inclusion in PubMed, CAS, Scopus and Google Scholar

- Research which is freely available for redistribution 